\title{
A VARIAÇÃO DAS REGÊNCIAS DOS VERBOS ASSISTIR E NAMORAR NO PORTUGUÊS BRASILEIRO E NO PORTUGUÊS LUANDENSE: UMA DISCUSSÃO SOBRE A FORMAÇÃO DO PORTUGUÊS BRASILEIRO
}

\author{
Manoel Crispiniano Alves da Silva ${ }^{1}$;
}

1. Bolsista PIBIC/FAPESB, Graduando em Letras Vernáculas, Universidade Estadual de Feira de Santana, e-mail: Silvamanoel403@yahoo.com.br

2. Silvana Silva de Farias Araújo, Departamento de Letras e Artes (DLA), Universidade Estadual de Feira de Santana, e-mail: Silvana.uefs.2014@gmail.com

PALAVRAS-CHAVE: Regência Verbal; Português Brasileiro; Português Angolano.

\section{INTRODUÇÃO}

Com o aparato teórico-metodológico da Sociolinguística Variacionista (LABOV, 1972), este trabalho teve o objetivo de investigar possíveis semelhanças ou diferenças a respeito do uso variável das regências dos verbos assistir e namorar no português falado em Luanda, capital de Angola, comparando os resultados alcançados com o uso das regências destes verbos no português falado em Feira de Santana-BA, sendo este representante do Português Brasileiro (doravante PB). Esta análise traz subsídios para melhor entender a formação da realidade sociolinguística brasileira, haja vista que pode lançar novas luzes a respeito da importância do contato linguístico na formação da identidade linguística do português falado no Brasil. Esta pesquisa buscou preencher uma lacuna no sentido de não apenas comparar os dados do PB ao Português Europeu (PE), mas ao português falado em uma ex-colônia de Portugal, Angola, pois "[...] para a compreensão do português brasileiro em geral, uma orientação antiga e tradicional, mas ainda viva que é a de buscar "influências" das línguas africanas no português brasileiro [...]" (MATTOS E SILVA, 2004, p. 93), para que possa ser medido o peso do contato linguístico entre ambas as nações.

\section{MATERIAL E MÉTODOS OU METODOLOGIA}

Utilizou-se o modelo teórico-metodológico da Teoria da Variação e Mudança Linguística, também denominada Sociolinguística Quantitativa, com base nas formulações de Weinreich, Labov e Herzog (2006[1968]) e Labov (2008[1972]). Esse é o modelo adotado em função de ser teoricamente coerente e metodologicamente eficaz para a descrição de uma comunidade de fala numa perspectiva da variação.

Para realização desta pesquisa, foram analisadas entrevistas sociolingüísticas do tipo DID (diálogo entre informante e documentador). Esta pesquisa teve como objetivo primordial, correlacionar o Português de Luanda (PL), no que concerne ao uso variável das regências dos verbos assistir e namorar. Para isso, foi necessária a análise de dois corpora linguísticos: o primeiro, com amostra de vinte e quatro (24) entrevistas gravadas na capital de Angola, Luanda, pertencente ao acervo do projeto de pesquisa "Em busca das raízes do português brasileiro", e o segundo com amostras da zona urbana do município de Feira de Santana- BA, que pertence ao acervo do projeto "A Língua Portuguesa do seminário baianoFase 3”. Estes projetos estão sediados no Núcleo de estudos da Língua Portuguesa (NELP) da Universidade Estadual de Feira de Santana (UEFS).

\section{RESULTADOS E/OU DISCUSSÃO}


Estudos realizados vêm mostrando semelhanças morfossintáticas entre a vertente popular do PL e a do PB (PETTER, 2007, 2009, 2015; TEIXEIRA, 2013). Os resultados aqui alcançados não apenas comprovam o que afirmam as autoras, mas amplia a discussão, mostrando que há uma aproximação muito grande entre as duas vertentes (a culta e a popular) da amostra da comunidade de fala de Luanda-Angola, apresentando um grau elevado de não padronização do PL. Nesse sentido, ressalta-se que, devido a pouca ocorrência do fenômeno estudado, ao que se atribui o fato de ser o verbo ver semanticamente igual ao verbo assistir, sendo aquele mais usado do que este, esta pesquisa é descritiva, não tendo sido possível realizar uma análise estatística, por meio do Programa computacional Goldvardb $X$ (SANKOFF, TAGLIAMONTE e SMITH, 2005).

$\mathrm{Na}$ norma popular de Luanda, é categórica a regência não padronizada do verbo namorar. Os exemplos a seguir, extraídos do corpus, servem para aclarar o resultado acima:

(01) [...]ah Antonica desde o primeiro dia que eu te vi eu gostei muito de te e eu tô afim denamorar contigo. Como tá afim de namorar comigo? Ser tem, a namorada que você tem ela é mulher, ela é bonita. Ah, Antonica! Eu tou a falar de te. Eu gostei de te, quero falar de te [...].

(02) Então quando cheguei, 74, me apareceu um noivo. Assim que me apareceu o noivo, começamos a namorar. Apresentei _nos meus pais. Assim que eu apresentei nos meus pais, pronto daí... Nós, antigamente, pra você namorar com um homem era só namorar assim, bocalmente.

(03) [...] Eu digo que não é correcta nada, não é correcta mesmo nada. Quer dizer o namoro daqui o namoro do Huambo é muito, muito diferente. Porque o namoro daqui pra pessoa ainda pode namorar com miúda enquanto que nem em casa, na casa da miúda nem sabes e nem saberes dizer que a nossa filha esta a andar com o fulano, mas enquanto que ela afinal já conhece que fulano que tá andar com ele [...]

(04) Não, não, não . Eu naquela altura quando eu comecei a namorar com ela eu estudava na escola Oliveira Salazar, que é actualmente a escola industrial. Conhece o Macarenco né?

Em relação ao verbo assistir, a regência preferida é a não padrão, houve apenas uma ocorrência da regência recomendada pelas gramáticas (BECHARA, 2009; CUNHA e CINTRA, 2007; ROCHA LIMA, 2011), ou seja, assistir a, mas pelo contexto, observa-se que houve um "efeito de gatilho" em que a informante foi influenciada pela fala do entrevistador, portanto, conclui-se que tal variante não faz parte do seu vernáculo, como pode ser constatado no exemplo a seguir:

DOC: "O que é que a tia utiliza? Assiste a televisão, vê o rádio ou lê os jornais?"

INFO:"Assisto a televisão"

DOC: "E na televisão quais são os programas que a tia gosto de assistir"

INFO: "Gosto de assistir o jogo, ver os nossos filhos a jogar e... Eu não sei como explicar"

Na norma culta, a regência não normativa do verbo assistir é preferível entre os angolanos, sendo $66,6 \%$. Em relação a namorar ocorre algo semelhante, chegando a $75 \%$ a não prescrita pelos compêndios gramaticais. Nota-se que há uma aproximação entre a norma popular e culta, apresentando o PL um alto grau de não padronização, aproximando-se, nesse sentido, dos resultados alcançados com a mostra de fala do português feirense. Diante dos dados alcançados, sentiu-se a necessidade de fazer um estudo contrastivo entre a fala de Feira de Santana-BA (corpus do projeto A língua portuguesa no semiárido baiano- Fase III), com 
os resultados de Luanda-Angola no que concerne ao uso das regências em debate. Foram encontradas em ambas as vertentes (culta e não culta) do português feirense, apenas uma ocorrência do verbo namorar. Em relação a assistir, na vertente culta, 94,5\% das ocorrências é a não padrão, sendo categórica a regência não normativa na vertente popular. Diante desses resultados, nota-se que a regência não prescrita pelos compêndios gramaticais é a preferida dos feirenses, havendo uma semelhança entre o PB e o PL, em relação a este fenômeno.

\section{CONSIDERAÇÕES FINAIS}

Diante dos resultados, esta pesquisa mostrou-se relevante e necessária por estudar um fenômeno que há poucos estudos a respeito do uso de tal variável no PL, e através dos dados podemos comprovar o que afirmam outros estudos sobre a aproximação do PL e do PB, tendo em vista o contato linguístico entre as duas nações. A partir dos resultados obtidos, essa pesquisa poderá dar uma contribuição significativa para melhor entender a contribuição africana na formação do PB, investigando as possíveis contribuições do contato linguístico para que hoje no Brasil, diferentemente de Portugal, e do que é prescrito pelos compêndios gramaticais, falemos assistir o e namorar com.

\section{REFERÊNCIAS}

BECHARA, Evanildo. Moderna gramática portuguesa. 37. ed. ver., ampl.e atual. Rio de Janeiro: Nova Fronteira, 2009.

CEGALLA, Domingos Paschoal. Novíssima gramática da língua portuguesa. 48.ed.rev.São Paulo: Companhia Editora Nacional, 2008.

CUNHA, Celso; CINTRA, Lindley. Nova Gramática Português Contemporâneo. 4.ed. Rio de Janeiro: Lexikon editora digital, 2007.

LABOV, William. Padrões sociolingüísticos. Tradução Marcos Bagno, Maria Marta Pereira Scherre, Caroline Rodrigues Cardoso. São Paulo: Parábola Editorial, 2008.

MATTOS E SILVA, Rosa Virgínia. Ensaios para uma sócio-história do português brasileiro. São Paulo: Parábola Editorial, 2004.

PETTER, Margarida Maria Taddoni. Uma hipótese explicativa do contato entre o português e as línguas africanas.Papia, v. 17, p. 9-19, 2007.

PETTER, Margarida MariaTaddoni.Aspectos morfossintáticos comuns ao português angolano, brasileiro e moçambicano. Papia, v. 19, p. 201-220, 2009.

PETTER, Margarida MariaTaddoni.Ampliando a investigação do continuum afro-brasileiro de português. Papia, v. 25, n. 2, p. 305-317, 2015.

ROCHA LIMA, Carlos Henrique da.Gramática normativa da língua portuguesa.49. ed.Rio de Janeiro: José Olympio, 2011.

SANKOFF, David; TAGLIAMONTE, Sali A.; SMITH, Eric.Goldvarb X:a multivariate analysis application. Toronto: Department of Linguistics; Ottawa: Department of Mathematics.

2005.

Disponívelem $<$ http://individual.utoronto.ca/tagliamonte/Goldvarb/GV_index.htm\#ref $>$ Acesso em 25. out.2011.

TEIXEIRA, Eliana S. Pitombo. Aspetos da pronominalização do português vernacular de Luanda: uma comparação com o português do Brasil.In: Norma da Silva Lopes; Lígia Pelon da Silva Bulhões; Cristina dos Santos Carvalho.(Org). Sociolinguística: estudo da variação, 
da mudança e da sócio-história do português brasileiro. Feira de Santana: EDUEFS, 2013, p.145-167.

WEINREICH, Uriel; LABOV, William; HERZOG, Marvin.Fundamentos empíricos para uma teoria da mudança lingüística.Tradução de Marcos Bagno; revisão técnica Carlos Alberto Faraco; posfácio de Maria da Conceição Paiva e Maria Eugênia L. Duarte. São Paulo: Parábola Editorial, 2006. 